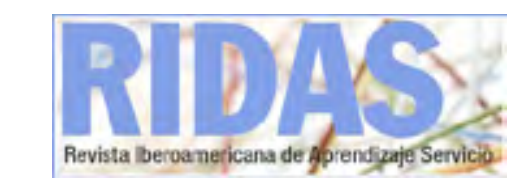

\title{
El compromiso social como pedagogía
}

\section{Reseña}

\section{Enrique Ochoa \\ CLAYSS, Argentina}

La obra El compromiso social como pedagogía. Aprendizaje y solidaridad en la escuela, de María Nieves Tapia, con Gerardo Bridi, María Paula Maidana y Sergio Rial (Bogotá, 2015) ha sido recientemente publicada por el CELAM (Consejo Episcopal Latinoamericano) como parte de la Colección Misión Transformadora (http://www.celam.org/publicaciones/ ficha. php?id=324).

La obra presenta sintéticamente los fundamentos pedagógicos y algunas herramientas para el desarrollo de proyectos educativos que integren aprendizaje formal y servicio solidario, a partir de la mirada y la experiencia latinoamericana, especialmente la desarrollada en los últimos 15 años.

El libro pone el foco en los

fundamentos y prácticas de aprendizaje servicio solidario en las instituciones educativas desde el nivel inicial hasta la finalización de la educación secundaria, abarcando las diferentes denominaciones y modalidades que en los países latinoamericanos definen la educación de niños y adolescentes entre los 4 y los 18 años.

Dado que esta obra es publicada y difundida por el CELAM, el texto pone en diálogo los conocimientos provenientes de la bibliografía pedagógica especializada con los aportes del magisterio de la iglesia católica, especialmente del Documento de Aparecida y del magisterio del Papa Francisco. Este libro puede resultar particularmente relevante para instituciones educativas católicas interesadas en 
integrar la vida pastoral y la vida académica en propuestas articuladas y superadoras, y que permita que educadores y estudiantes fortalezcan la síntesis entre conocimientos, compromiso social y fe cristiana. Al mismo tiempo, sabiendo que la pedagogía del aprendizaje servicio solidario se ha desarrollado en los más diversos contextos culturales en nuestro continente y a nivel mundial, y que es una propuesta válida para el conjunto de las instituciones educativas, tanto públicas como privadas, laicas o confesionales, asumida como tal desde las políticas educativas de varios de nuestros países, este libro puede ser útil también para educadores e instituciones no católicos.

La obra aborda, con profundidad y detalle, las características fundamentales del aprendizaje servicio solidario: la solidaridad, el protagonismo estudiantil y la articulación de los aprendizajes con el servicio solidario.

En la primera parte se presentan los fundamentos conceptuales de la propuesta del aprendizaje servicio solidario, así como relatos de las prácticas de diversas instituciones educativas de la región que pueden servir como punto de referencia.
A menudo, como educadores necesitamos marcos teóricos de referencia, pero también poder aprender horizontalmente de las experiencias de otros educadores y otras instituciones. Por obvias razones de nacionalidad de los autores, se relatan con mayor detalle experiencias de escuelas argentinas, pero también se incluyen experiencias representativas del resto de América Latina y el Caribe. Luego se presentan diferentes puntos de partida desde los cuales comenzar a desarrollar proyectos de aprendizaje servicio solidario.

Se propone la revisión y el análisis de diversas formas en que las instituciones educativas se vinculan con la comunidad, buscando la institucionalización de los proyectos educativos solidarios. Se revisan 
algunas ideas vinculadas al concepto de solidaridad, recogiendo una gran diversidad de significados que el mismo adopta en diferentes lugares y circunstancias, adhiriendo a la idea de una solidaridad "inteligente" que logre dar respuestas a las problemáticas sociales que la desafían. Como una guía para los que se inician en la temática, y producto del análisis de experiencias de diferentes y variadas instituciones educativas, se presenta un itinerario posible para el desarrollo de los proyectos.

En la segunda parte, se ofrecen algunas herramientas prácticas para el desarrollo de proyectos, así como información de utilidad y bibliografía para seguir profundizando el tema. Al tratarse de una actualización y reconceptualización del estado de los conocimientos sobre las prácticas de aprendizaje servicio solidario en la escuela, el libro resulta de interés tanto para quienes recién se inician en la temática como para aquellos que ya vienen desarrollando proyectos educativos solidarios, han participado en diferentes instancias de capacitación y desean profundizar y actualizar aspectos teóricos y prácticos de la propuesta. 